Int. J. Dev. Biol. 61: 649-654 (2017)

doi: 10.1387/ijdb.170105tl

\title{
Interpreting amphioxus, and thoughts on ancestral chordate mouths and brains
}

\author{
THURSTON LACALLI* \\ Biology Department, University of Victoria, Victoria, Canada
}

\begin{abstract}
Amphioxus is increasingly important as a model for ancestral chordates. Nevertheless, it is secondarily modified in various ways, especially in the larva, whose small size has resulted in a rescaling and repositioning of structures. This is especially pronounced in the head region, where the mouth opens asymmetrically on the left side, leading to speculation that the mouth is secondarily derived, e.g. from a gill slit, and is hence not homologous with mouths in other animals. The available evidence does not, in the author's view, support this interpretation. A second issue is raised concerning the identity and function of the midbrain homolog, whose extent depends on whether greater weight is given to dorsal landmarks in the nerve cord or ventral ones. The presence of two sets of dorsal photoreceptors, the lamellar body and Joseph cells, functionally links the region they occupy to the vertebrate midbrain. The midbrain is currently suggested to be the brain region in which primary consciousness emerged during early vertebrate evolution, so the origin of its constituent cells is of special interest. Possible amphioxus homologs include the anterior-most group of dorsal bipolar cells (ADBs), which are apico-basally inverted (i.e. synapse-bearing neurites arise from the apical cell compartment) in the same fashion as cortical neurons in vertebrates. This may have been a crucial innovation for chordates, responsible for both improved sensory processing and, eventually, consciousness.
\end{abstract}

KEY WORDS: chordate bodyplan, midbrain, vision, consciousness

\section{Introduction}

There is a substantial evolutionary gap between chordates and their nearest invertebrate relatives, echinoderms and hemichordates. Only amphioxus provides anything close to a model for how that gap might be bridged, having now replaced tunicates in this role (LZ Holland 2015). In consequence, a good deal of past speculation about ancestral chordates and vertebrate origins now needs to be re-examined with amphioxus placed closer to center stage.

A key problem interpreting amphioxus in a phylogenetic context has always been to distinguish between features that reflect the ancestral condition and those that are secondarily derived. This has resulted in conflicting evolutionary scenarios, some quite unconventional, which need careful assessment if the key events of early chordate evolution are to be fully understood. I illustrate this point below, using two examples, one concerning the nature and origin of the mouth in amphioxus, the other the location and extent of its midbrain homolog. The latter is currently of special interest because of the possible involvement of this part of the brain in the origin of consciousness. The focus here is on early development and the larval stage, and this raises special interpretive problems owing to the exceedingly small size of amphioxus embryos and larvae compared with those of vertebrates. The consequences of this difference in scale need to be appreciated, and so are addressed at the outset.

\section{Size constraints and routes to evolutionary innovation}

Basal deuterostomes have simple ciliated larvae and develop from eggs ranging from one to two hundred microns in diameter, for species with feeding larvae, to a millimeter or so for the yolkiest eggs of species with non-feeding larvae. Amphioxus eggs contain a modest amount of yolk and fall into the former category. Whether

Abbreviations used in this paper: ADBs, anterior group of dorsal bipolar neurons; alm anterolateral migrated cell group; CNS central nervous system; CSG club-shaped gland; DN, dorsal nerve tract; inf, infundibular cell; ESC, epithelial sensory cell;JC, Joseph cell; LPNs large paired neurons; LMB lamellar body; MLR mesencephalic locomotor region; PMC primary motor center; psz primary synaptic zone; TEM transmission electron microscopy.

\footnotetext{
*Address correspondence to: Thurston Lacalli. Biology Department, University ofVictoria, Victoria, BC,V8W-3N5, Canada.Tel:+1-(250) 721-7095. Fax+1-(250) 721-7120. E-mail: lacalli@ uvic.ca (iD) http://orcid.org/0000-0003-3123-7062
} 
they were once much larger is not clear, but there is no specific reason to suppose so, and the blastula and gastrula are simple, ciliated and not dissimilar from comparable stages in other invertebrates (Hirakow and Kajita 1991). The notochord rudiment, neural plate and somites begin to appear at the neurula stage, and from there the larva becomes increasingly chordate-like in appearance (Hirakow and Kajita 1994; Stokes and Holland 1995). As to where these chordate features come from, there are two possibilities. In scenarios deriving chordates from the larvae of tunicates, the supposition was that the structures in question evolved as locomotory aids for the motile larva, and either the adult stage acquired them secondarily, or the larvae, through a process of heterochrony, acquired gonads and thereby replaced what had been the adult stage. Ideas of this type have fallen out of favor as tunicates have been displaced from their supposed basal position in the chordate lineage (Lacalli 2005; ND Holland 2011). The alternative view is that the features characteristic of chordates evolved in an adult that, with increasing efficiency, took to swimming. The larval stage would then have acquired its chordate-specific features secondarily, again by heterochrony, with precocious differentiation moving them ever earlier in the life history. This process is known more generally as adultation (Jagersten 1972), and occurs in diverse invertebrate taxa, notably annelids and mollusks, such that larvae in various lineages become, over evolutionary time, progressively more adult-like.

A problem with adultation is that, without an accompanying increase in egg size, progressively more organs and structures have to be constructed from a small, existing pool of embryonic cells. Individual organs and structures therefore tend towards being as small as is functionally possible, and the development of less essential features may be delayed. That this has occurred in amphioxus is evident in the CNS: ventral sets of motor and premotor interneurons differentiate early in development, while dorsal neurons are delayed in their development until the larvae have been feeding for some days and have begun to grow (Wicht and Lacalli 2005). The ventral neurons must therefore be essential components of the locomotory circuits, while the dorsal ones are less important, so their development can be delayed. In vertebrate embryos, owing to a much larger nutrient supply to the egg, there is sufficient time and cell numbers to form both types of circuits before hatching. Whatever differences there may be in timing, they are not nearly so pronounced as in amphioxus.

The hatching larva of amphioxus is a remarkable example of how much anatomical structure can be packed into a small space: at slightly over $1 \mathrm{~mm}$ in length when it first begins to swim actively (Fig. 2 in Mansfield et al., 2015 shows the growth sequence), it is arguably the smallest known example of a fully realized chordate body. It is therefore not surprising that some structures fit rather uncomfortably in the available space. The problem is particularly acute in the head, which is crammed with structures associated with the rostral extension of the notochord and somite series, including accessory organs needed to serve the functional demands of the latter. Hatschek's nephridium may be one such example, needed because the head region has become metabolically more active prior to the time the caudal nephridia associated with the pharyngeal gill slits become functional. There may be consequences also in terms of developmental mechanism since, once a tissue domain has been reduced to a handful of cells, differentiation is likely to depend more on cell-to-cell interactions than on longer range signaling. This may explain why amphioxus seems not to require a full complement of vertebrate-type CNS signaling centers, an issue discussed at greater length by L. Z. Holland et al., (2013).

\section{The mouth: repositioned or entirely new?}

Mouth formation in amphioxus is unusual among chordates for being highly asymmetrical, as the mouth appears first on the left side of the head and only shifts to the ventral midline at metamorphosis. This peculiar situation has led to suggestions that the amphioxus mouth may be an entirely novel structure, unrelated to mouths in other chordates, and derived secondarily from some other lateral structure. The anterior-most left gill-slit is one such candidate, suggested first by van Wijhe (1913), and a nearby coelomoduct has also been proposed (Kaji et al., 2016).

The more conventional and simplest explanation for larval head asymmetry is that the head is too narrow to accommodate the mouth, except by shifting it to one side (Bone 1958; Presley et al., 1996). In the context of the adultation scenario discussed above, the ventral mouth of the adult would be the expected ancestral condition, and any alteration to that in the larva would be a secondary modification. A complication here is that chordates appear to be dorsoventrally inverted relative to non-chordates (e.g. see Lowe et al., 2015), which means the ventral mouth of adult amphioxus would already have undergone an earlier postinversion shift, from a dorsal location like that in tunicates to a ventral one comparable to that in vertebrates (Veeman et al., 2010). Shifting the larval mouth to the left side in amphioxus would then be something that accompanied the heterochronic process that made the larva progressively more chordate-like, while the differential growth process that moves it back to the ventral midline would simply restore the adult condition. It is now known that head asymmetry in amphioxus is under the control of Nodal signaling (Soukup et al., 2015) and surprisingly, blocking Nodal not only eliminates the mouth, but also two accessory oral structures, the external opening and duct of the club-shaped gland (CSG) and the preoral pit. The pharynx, in contrast, becomes symmetrical and the upper, secretory portion of the CSG is duplicated. These observations are striking, and prompt two comments.

First, they accord with the inference one can make from the pattern of differential growth required to restore pharyngeal symmetry during metamorphosis. If a single patterning system were responsible for positioning both the mouth and pharyngeal structures (e.g. endostyle and gill slits), as would be the case if the mouth was derived from a pharyngeal structure, restoring symmetry at metamorphosis would require a highly, perhaps impossibly, complex pattern of differential growth (for details, see Lacalli 2008a). Without such linkage, the growth pattern is much simpler. This suggests strongly that the mechanism specifying mouth position is entirely independent of that acting to pattern the pharynx. Hence the mouth is unlikely to be linked to other pharyngeal structures through homology.

Second, the fact that the mouth, preoral pit and the CSG ducts disappear together when Nodal is blocked may be telling us something useful about the ancestral condition. The restoration of pharyngeal symmetry eliminates what is likely a derived feature so far as the pharynx itself is concerned, i.e. its asymmetry. That the mouth itself is not restored suggests that a Nodal-dependent response element has been irreversibly altered in amphioxus evo- 
lution, but also that the other missing structures were themselves once arrayed around the ancestral mouth. If we project these back to the position they and their openings would have occupied at the time of dorsoventral inversion, we get a dorsal mouth with paired CSGs opening on either side, and a preoral pit positioned medially either in front or behind. The amphioxus CSG releases its secretion internally, probably to contribute to the mucus net, while the preoral pit produces a modest amount of external secretion that enters the mouth with food particles. The positioning of three mucus-secreting accessory organs immediately around the mouth in the supposed ancestor suggests that feeding then also depended heavily on the production of both internal and external mucus nets, perhaps to an even greater degree than in basal chordates today. The point is reinforced by genomic data (Simakov et al., 2015) on the innovations deuterostomes have made in the biochemical pathways involved in mucus production, as this could well have been driven by changes in the method of food capture or the need to improve its efficiency.

The idea that the amphioxus mouth is secondarily derived from a gill slit or coelomoduct deserves some further comment here. The appeal of such ideas comes in part from similarity in the relationship between the duct of Hatschek's nephridium and the mouth compared with that between the openings of the serial trunk nephridia and each of the gill slits, and there is renewed interest in the subject following a report by Kaji et al., (2016) of a spherical aggregation of mesodermal cells associated with the developing nephridium that, in their view, contributes directly to the mouth opening. If true, this would raise a number of questions about other head structures and their homologies, well summarized by Soukup and Kozmik (2016), but doubts have been raised concerning the supporting data, including the validity of BMP2/4 expression observed in the oral region (Yong et al., 2017). In addition, the basal lamina in this region is delicate, which means the arrangement of cells in fixed preparations can be labile and easily misinterpreted, and one needs to rule out, in any case, that the cells in question are not simply precursors of the oral musculature, which is substantial (Lacalli et al., 1999). In sum, there are unanswered questions about the observations of Kaji et al., and a need for further work, including tracer studies to establish cell fates. Explanations that rely on unconventional evolutionary derivations are provocative, but need strong, unambiguous supporting evidence.

A final question about Hatschek's nephridium concerns its homology. Its rostral location, well forward of any vertebrate excretory structures, is curious, and most likely reflects the need for a kidney to serve the needs of the anterior-most myotomes, as already mentioned. It must then derive from one of the anterior coeloms characteristic of basal deuterostomes, but which one? Current evidence points strongly to the amphioxus homolog of the left mesocoel, because both the nephridium and the first myotome on the left, from which Hatschek's nephridium develops, are positioned in register with the dien-mesencephalon, whose counterpart in hemichordates coincides with the mesocoel (Zieger et al., 2017). Despite occasional confusion in the literature on this point, this accords with the generally accepted interpretation that the protocoel homologs in amphioxus are the first pair of enterocoels, Hatschek's diverticula, which develop separately from the somite series and lie rostral to the first pair of myotomes.

\section{Amphioxus midbrain, vision, and the origin of con- sciousness}

A combination of molecular and serial TEM investigations of the anterior nerve cord in amphioxus embryos and larvae have revealed enough similarities with vertebrate brain to allow homologous regions to be tentatively identified (Wicht and Lacalli 2005, Lacalli 2008b, LZ Holland 2009, LZ Holland et al., 2013). Not all parts of the vertebrate brain are clearly represented in amphioxus, however. It remains unclear, for example, whether amphioxus has a homolog of the telencephalon, or if so, how much of one. The midbrain homolog is also problematic, in that structures normally associated with midbrain lie within a domain that, based on its molecular signature, combines diencephalon and mesencephalon together (Albuixech-Crispo et al., 2017). This dien-mesencephalic domain extends from the infundibular cells and the front of the lamellar body to approximately the end of somite 1 , and is roughly equivalent to the posterior cerebral vesicle as defined by Lacalli et al., (1994). Despite the absence of identifiable subdomains, there must nevertheless be a point along the anteroposterior axis of the dien-mesencephalon where a region that maps to vertebrate diencephalon transitions to one that maps instead to midbrain, but the morphological data (see Fig. 1) are in conflict as to where this might be. Dorsal landmarks imply the diencephalic component is quite large, because the lamellar body, almost certainly a pineal homolog, extends by the end of the larval phase to the end of somite 1 (Fig. $1,2^{\text {nd }}$ line from the top). This leaves minimal space for a midbrain homolog of any size because Hox expression, a hindbrain marker, begins in the first half of somite 2. Ventral landmarks, in contrast (Fig. 1, bottom line), imply a larger midbrain homolog, beginning perhaps as far forward as the infundibular cells, and including both the principal site of synaptic input to the escape response (the primary synaptic zone, psz in Fig. 1) and the primary motor center (PMC), a putative homolog of the vertebrate mesencephalic locomotor region (MLR). Infundibular cells are secretory and supposed to be homologous, as a group, to the vertebrate subcommissural organ, located at the front of the midbrain (Olsson 1986). There is a problem with this interpretation, highlighted by Albuixech-Crispo et al., (2017), in that the rostral end of the floor plate abuts the infundibular cells in amphioxus, but extends beneath the diencephalon in vertebrates to the hypothalamus. From the molecular evidence, the amphioxus infundibular organ would appear instead to correspond most closely in location with the zona limitans intrathalamica, which means it lies within the confines of the diencephalon. In consequence, however far forward any putative midbrain homolog extends in amphioxus, it does not reach the level of the infundibular cells.

The molecular evidence for a unitary dien-mesencephalic domain in amphioxus seems compelling, so long as it is not a secondarily simplified condition caused by the loss of signaling centers like the zona limitans and isthmus organizer. Setting this issue aside, one still wants to know which parts of this domain are most closely allied, either in terms of relative position, structures or both, with vertebrate midbrain. Why is this important? First, we have no good idea currently as to how any of the dorsal sensoryprocessing centers of the vertebrate brain originated in evolution, including the optic tectum, the principle site in lower vertebrates for processing visual input. Nor do we know why this function 


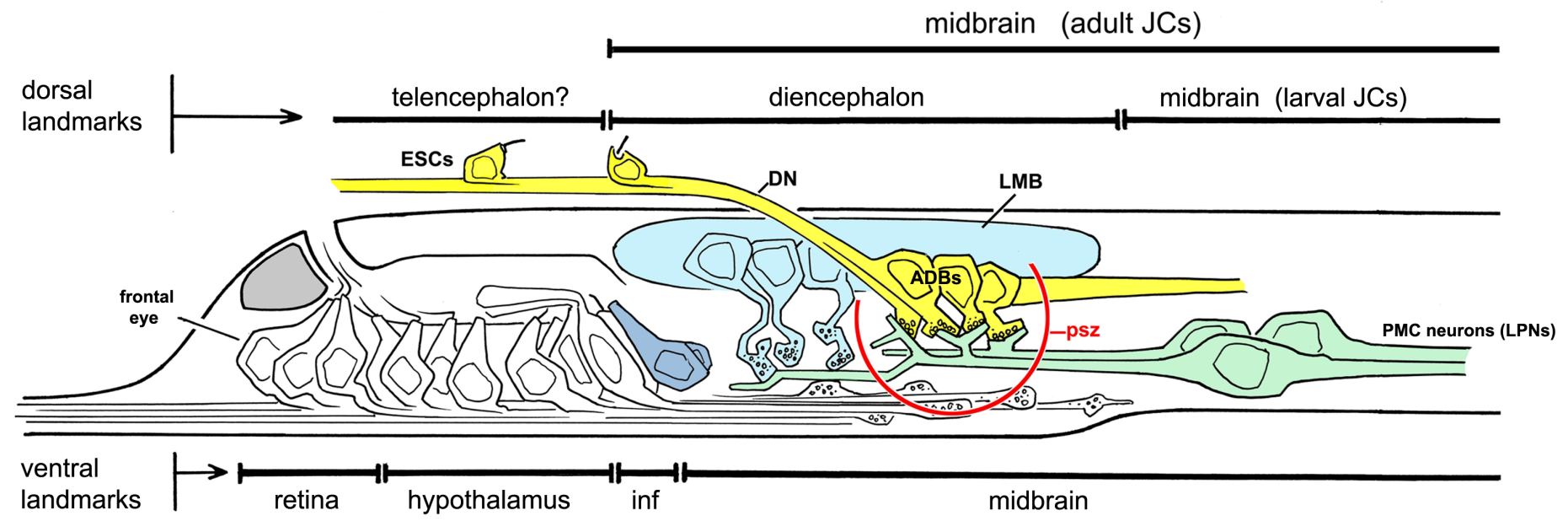

Fig. 1. Schematic side view of the anterior nerve cord of an amphioxus larva, from TEM reconstructions of a 12-day B. floridae larva. The cellS of the escape circuit are highlighted in color; see Wicht and Lacalli 2005, for further information. The primary synaptic zone (psz, circled in red) is where the axons of epithelial sensory cells (ESCS) entering the cord via the first pair dorsal nerves (DN, yellow) first encounter and synapse to dendrites belonging to the principle interneurons (LPNs, green) of the primary motor center (PMC), which are a major source of excitatory input to the escape response. Inputs are also received here from the anterior group of bipolar cells (ADBs, also yellow) located on either side of the lamellar body (LMB, light blue) about half way along its length. It is not clear whether the region where this occurs is closer to forebrain or midbrain in terms of homology. The landmarks are ambiguous on this point as shown: for the larva, the dorsal lamellar body, a pineal homolog, can be used provisionally to mark the axial extent of the diencephalon, but this conflicts with the view that the ventral cluster of infundibular cells (inf, in dark blue) mark the beginning of the midbrain. A complication is that the situation in the adult is somewhat different since, based on B. lanceolatum (Ruppert 1997), the rhabdomeric Joseph cells (JCS) extend to the anterior end of the lamellar body. This implies an overlap between a diencephalic marker and one that has no known association with diencephalon, but is instead, usually associated with more caudal CNS domains.

is carried out in the roof of the midbrain rather than some other location. In adult amphioxus, the dien-mesencephalon is home to two separate photoreceptor systems, the lamellar body and the Joseph cells (Fig. 1, top line). The former, a pineal homolog, is a poor candidate for a precursor of a center for processing visual images; the Joseph cells may be better. They are described as primary photoreceptors by Welsch (1968), but are rhabdomeric and have no obvious vertebrate counterpart, so we do not know whether they were even present in the common ancestor of amphioxus and vertebrates. If they were, however, there would be some justification for supposing that the role the midbrain plays in visual processing in vertebrates might have begun as an association between a similar set of now vanished rhabdomeric photoreceptors and the neurons located immediately beneath. This, in itself, justifies investigating these cells further, and the brain region they occupy, for cells or circuitry that might have been co-opted into the vertebrate tectum during its evolution.

There is a final, and quite important reason for pursuing this particular issue: the suggestion, explored at some length by Feinberg and Mallatt $(2016 \mathrm{a}, \mathrm{b})$, that the midbrain is where primary consciousness evolved in vertebrates and, more specifically, that the visual system and optic tectum were directly involved. If these authors are correct, any search for the neural circuits responsible for consciousness should begin with the tectum in lower vertebrates, its output circuits and targets. If precursors to these cells and circuits are present in amphioxus, even in rudimentary form, the place to look for them is in the amphioxus homolog of the midbrain.

In this context, there are two aspects of consciousness that need to be considered, the experience of vision and of "affect". The latter is a term for the conscious aspect of motivational preference (see Feinberg and Mallatt 2016a), and has positive and negative (i.e. pleasure- or pain-like) aspects. For amphioxus, without an imageforming eye, we are on somewhat shaky ground when it comes to assessing what amphioxus might experience of its surroundings in visual terms. But the experience of pain, and specifically sharp pain, is easier to imagine for any animal at risk of being grabbed by predators and chewed upon. Amphioxus responds to such events by escape behavior, and we have a fairly clear idea of the circuits involved, in the early-stage larva at least. The key synaptic nexus is the above-mentioned psz (see Fig. 1), where the main PMC interneurons receive synaptic input from the rostral and dorsal sensory nerves, and from the anterior group of dorsal bipolar neurons (ADBs).

There is no evidence, nor expectation, that amphioxus larvae have any conscious awareness of sensory stimuli impinging on the psz or any other such site. At some point in evolution, however, in an ancestral fish according to Feinberg \& Mallatt (2016a), a suitably processed neural signal would have been experienced as a sharp pain-like sensation for the first time. Feinberg and Mallatt focus, in their analysis, on the need for complex, multilevel integrative circuits to produce this result, though currently the nature of such circuits is entirely unknown. The expected level of complexity is not evident in the CNS of young amphioxus larvae, but could be present in older larvae or the adult. In particular, I would point to the increase in the numbers of translumenal neurons that develop during the larval phase and come to dominate the anterior, brainlike portion of the CNS (e.g. Castro et al., 2015). These neurons remain attached to neural epithelium, but have apical processes that cross the central canal and enter the neuropile on the contralateral side. TEM evidence shows they participate in complex modulatory circuits in young larvae (Lacalli and Kelly 2003), and could, with further development, increase the integrative capabilities of the 
adult brain to a significant degree. It is not clear whether such cells are in any way related to those performing integrative functions in vertebrates, e.g. in the cortex or optic tectum, but it is worth noting that, from my own observations, late-stage amphioxus larvae and adults struggle vigorously when physically constrained in essentially in the same way that fish do in similar circumstances, suggesting whatever mechanism the latter rely on to drive the animal to this level of activity may have a counterpart in amphioxus.

Beside integrative complexity, a second thing to look for in any putative consciousness circuit is amplification. This is not simply a matter of increasing the total number of synapses, because developing organisms like amphioxus larvae face the problem of gain control, that is, of not swamping the system with ever increasing levels of unmodulated input (Priebe and Ferster 2002). Rather, one is looking for sensory circuits whose output can be selectively amplified so as to galvanize the animal into action when required. Of special interest in this context is a class of amphioxus neurons referred to as "migrated neurons" (Wicht and Lacalli 2005) for the fact that they detach from the neural canal and move outwards into the neuropile. In young larvae these are limited to the ADBs, which are sources of synaptic input to the psz independent of that from epithelial sensory cells. The ADBs are joined at later stages by cells of presumably similar type, which together form a population of some size along the sides of the anterior neuropile (the anterolateral migrated cell group, or alm, see Wicht and Lacalli 2005), and by cells of unknown function that cluster around the margins of the Joseph cells and near the entry point of the first dorsal nerve. Whether ADBs, or any of the other migrated cells are involved in the production of signals amplified sufficiently to become, in some sense, conscious, any response would be routed of necessity through the psz. The cells and circuits providing input to the psz are thus the first place one would look for evidence of a neural basis for some form of heightened sensation. It is worth noting that the ADBs supply a tract where reciprocal interactions between cells and fibers could generate positive feedback of the appropriate kind. I have searched for evidence of reciprocal synapses between these cells in young larvae without result, but there are regions of close contact between axons within the dorsal tracts that could produce a similar result by non-synaptic means, and more complex synaptic circuits involving these cells could well develop as the CNS matures.

The ADBs are noteworthy also for being apico-basally inverted relative to most other amphioxus neurons (see Figs. 21-24 in Lacalli 1996, where the ADBs are referred to as tectal cells). Inversion, in this instance, refers to the fact that, while most amphioxus neurons have apical cilia and basal axons, the synaptic terminals of the ADBs are borne on short processes emerging from the cell body that cluster around the centrioles and Golgi, which, because of their close association with the ciliary rootlet, serve as provisional markers for the apical compartment of the cell. Vertebrate neural precursors, when extracted from cerebral cortex, are also inverted (Barnes and Polleux 2009), and it is these same neurons that perform the most complex integrative functions in the brain. A further similarity is that, as with excitatory cortical neurons, the ADBs appear to use glutamate as a transmitter (Lacalli and Candiani 2017). It may be more than a coincidence that inversion and complex integrative function are linked, suggesting that the evolutionary event that produced the former may have been responsible, ultimately, for the latter.
When it comes to positive affect, i.e. a motivational circuit that is "pleasure-like", the relevant cells to investigate are the dopaminergic neurons, which are now better known in amphioxus from the work of Zieger et al., (2017). A different kind of amplification may be involved here, in that the dopaminergic system seems to function as a means of recruiting additional cells and pathways in order to sustain the swimming response once it's initiated. Put simply, in this presumably pre-conscious, larval, amphioxus-level motivational system, negative affect may have more of a role in initiating the escape response, and positive affect for sustaining it. Whether or not such a simple analysis is borne out by further investigation, amphioxus provides a unique opportunity to study the basis in circuitry for motivational decision-making in chordates in an especially simple form. Discovering the sources of conscious thought is a daunting task, but there are places where one can begin to look.

\section{Acknowledgments}

This work was supported by NSERC Canada and the Lionel G. Harrison Research Trust. The author thanks Vladimir Soukup for additional information on his Nodal experiments, Jon Mallatt and Nick Holland for comments on earlier drafts of the paper, and Heather Down for assistance preparing figures.

\section{References}

ALBUIXECHI-CRESPO B, LOPEZ-BLANCHL, BURGUERAD, MAESOI, SANCHEZARRONESL, MORENO-BRAVOJA, SOMORJAII, PASCUAL-ANAYAJ, PUELLES E, BOVOLENTA P, GARCIA-FERNANDEZ J, PUELLES L, IRIMIA M, FERRAN $J \mathrm{~L}$ (2017). Molecular regionalization of the amphioxus neural tube challenges major partitions of the vertebrate brain. PLoS Biol 15: 4.

BARNESAP, POLLEUXF (2009). Establishment of axon-dendrite polarity in developing neurons. Ann Rev Neurosci 32: 347-381.

BONE Q (1958). The asymmetry of the larval amphioxus. Proc Zool Soc Lond 130 289-293.

CASTRO A, BECERRA M, MANSO M J, ANADON R (2015). Neuronal organization in the brain in the adult amphioxus (Branchiostoma lanceolatum): a study with acetylated tubulin immunohistochemistry. J Comp Neurol 523: 2211-2232.

FEINBERG T E and MALLATT J M (2016a). The Ancient Origins of Consciousness. MIT Press, Cambridge, Mass.

FEINBERG TE, MALLATT J M (2016b). The nature of primary consciousness. A new synthesis. Consciousness Cogn 43: 113-127.

HIRAKOW R, KAJITA N (1991). An electron microscopical study of amphioxus, Branchiostoma belcheri: the gastrula. J Morph 207: 37-52.

HIRAKOW R, KAJITA N (1994). An electron microscopical study of amphioxus Branchiostoma belcheri: the neurula and larva. Acta Anat Nipp 69: 1-13.

HOLLAND L Z (2009). Chordate roots of the vertebrate nervous system: expanding the molecular toolkit. Nat Rev Neurosci 10: 736-746.

HOLLAND L Z (2015). Genomics, evolution and development of amphioxus and tunicates: the Goldilocks principle. J Exp Zool (Mol Dev Evol) 324: 342-352.

HOLLAND L Z, CARVALHO J E, ESCRIVA H, LAUDET V, SCHBERT M, SHIMELD $S$ M, YU J K (2013). Evolution of the bilaterian central nervous system: a single origin? EvoDevo 4: 2

HOLLAND N D (2011). Walter Garstang: a retrospective. Theory Biosci 130: 247-258. JAGERSTENG (1972). Evolution of the Metazoan Life Cycle. Academic Press, London.

KAJI T, REIMER J D, MOROV A R, KURATANI S, YASUI K (2016). Amphioxus mouth after dorso-ventral inversion. Zool Lett 2: 2

LACALLI T C (1996). Frontal eye circuitry, rostral sensory pathways and brain organization in amphioxus larvae: evidence from 3D reconstruction. Phil Trans $R$ Soc Lond B351: 243-263.

LACALLI T C (2005). Protochordate body plan and the evolutionary role of larvae: old controversies resolved? Can J Zool 83: 216-224. 
LACALLI T C (2008a). Mucus secretion and transport in amphioxus larvae: organization and ultrastructure of the food trapping system, and implications for head evolution. Acta Zool 89: 219-230.

LACALLIT C (2008b). Basic features of the ancestral chordate brain: a protochordate perspective. Brain Res Bull 75: 319-323.

LACALLI T C, GILMOUR T H J, KELLY S J (1999). The oral nerve plexus in amphioxus larvae: function, cell types and phylogenetic significance. Proc $R$ Soc Lond B266: 1461-1470.

LACALLI T C, KELLY S J (2003). Sensory pathways in amphioxus larvae II. Dorsal tracts and translumenal cells. Acta Zool 84: 1-13.

LACALLI T C, CANDIANI S (2017). Locomotory control in amphioxus larvae: new insights from neurotransmitter data. EvoDevo 8: 4.

LOWE C J, CLARKE D N, MEDEIROS D M, ROKHSAR D S, GERHART G (2015). The deuterostome context of chordate origins. Nature 520: 456-465.

MANSFIELD J H, HALLER E, HOLLAND N D, BRENT A E (2015). Development of somites and their derivatives in amphioxus, and implications for the evolution of vertebrate somites. EvoDevo 6: 21.

OLSSON R (1986). Basic design of the chordate brain. In Indo-Pacific Fish Biology (Eds TUyeno, RArai, T Taniuchi and K Matsuura). Ichthyological Soc. Japan, pp. 86-93.

PRESLEY R, HORDER T J, SLIPKA J (1996). Lancelet development as evidence of ancestral chordate structure. Isr J Zool 42: S97-S116.

PRIEBE N J, FERSTER D (2002). A new mechanism for neuronal gain control (or how the gain in brains has mainly been explained). Neuron 35: 602-604.

RUPPERT E E (1997). Cepalochordata (Acrania). In Microscopic Anatomy of Invertebrates, vol 15 (Eds F W Harrison and E E Ruppert). Wiley-Liss, New York, pp. 349-504.
SIMAKOV O, et al., (2015). Hemichordate genomes and deuterostome origins Nature 527:459-465

SOUKUP V, YONG L W, LU T M, HUANG S W, KOZMIK Z, YU J K (2015). The Nodal signaling pathway controls left-right asymmetric development in amphioxus. EvoDevo 6:5.

SOUKUP V, KOZMIK Z (2016). Zoology: a new mouth for amphioxus. Curr Biol 26 R355-R376.

STOKES M D, HOLLAND N D (1995). Embryos and larvae of a lancelet, Branchiostoma floridae, from hatching through metamorphosis: growth in the laboratory and external morphology. Acta Zool 76: 105-120.

VAN WIJHE J W (1913). On the metamorphosis of Amphioxus lanceolatus. Proc Kon Akad Wetensch Ser 2 16: 574-583.

VEEMAN M T, NEWMAN-SMITHE, EL-NACHEF D, SMITH W C (2010). The ascidian mouth opening is derived from the anterior neuropore: reassessing the mouth/ neural tube relationship in chordate evolution. Dev Biol 344: 138-149.

WICHT H, LACALLI T C (2005). The nervous system of amphioxus: structure, development, and evolutionary significance. Can J Zool 83: 122-150.

WELSCH U (1968). Die Feinstruktur der Josephschen Zellen im Gehirn von Amphioxus. Zeit Zell Mikros Anat 86: 252-261.

YONG L W, BERTRAND S, YU J K, ESCRIVA H, HOLLAND N D (2017). Conservation of BMP2/4 expression patterns within the clade Branchiostoma (amphioxus): resolving interspecific discrepancies. Gene Exp Pat 25/26: 71-75.

ZIEGER E, LACALLI T, PESTARINO M, SCHUBERT M, CANDIANI S (2017). The origin of dopaminergic systems in chordate brain: insights from amphioxus. Int J Dev Biol 61: 749-761. 


\section{Further Related Reading, published previously in the Int. J. Dev. Biol.}

From the American to the European amphioxus: towards experimental Evo-Devo at the origin of chordates

Jordi Garcia-Fernàndez, Senda Jiménez-Delgado, Juan Pascual-Anaya, Ignacio Maeso, Manuel Irimia, Carolina Minguillón, Ėlia BenitoGutiérrez, Josep Gardenyes, Stéphanie Bertrand and Salvatore D'Aniello

Int. J. Dev. Biol. (2009) 53: 1359-1366

https://doi.org/10.1387/ijdb.072436jg

Evolution of CUT class homeobox genes: insights from the genome of the amphioxus, Branchiostoma floridae Naohito Takatori and Hidetoshi Saiga

Int. J. Dev. Biol. (2008) 52: 969-977

https://doi.org/10.1387/ijdb.072541nt

Peter Holland, homeobox genes and the developmental basis of animal diversity

Sebastian M. Shimeld

Int. J. Dev. Biol. (2008) 52: 3-7

https://doi.org/10.1387/ijdb.072394ss

Developmental expression of the High Mobility Group B gene in the amphioxus, Branchiostoma belcheri tsingtauense

Xiangwei Huang, Lifeng Wang and Hongwei Zhang

Int. J. Dev. Biol. (2005) 49: 49-46

http://www.intjdevbiol.com/web/paper/041915xh

Cell morphology in amphioxus nerve cord may reflect the time course of cell differentiation

T C Lacalli

Int. J. Dev. Biol. (2000) 44: 903-906

http://www.intjdevbiol.com/web/paper/11206331

Embryonic development of heads, skeletons and amphioxus: Edwin S. Goodrich revisited P W Holland

Int. J. Dev. Biol. (2000) 44: 29-34

http://www.intjdevbiol.com/web/paper/10761843

Amphioxus Hox genes: insights into evolution and development

$\mathrm{J}$ Garcia-Fernàndez and $\mathrm{P}$ W Holland

Int. J. Dev. Biol. (1996) 40: S71-S72

http://www.intjdevbiol.com/web/paper/9087701

5 yr ISI Impact Factor $(2013)=2.879$
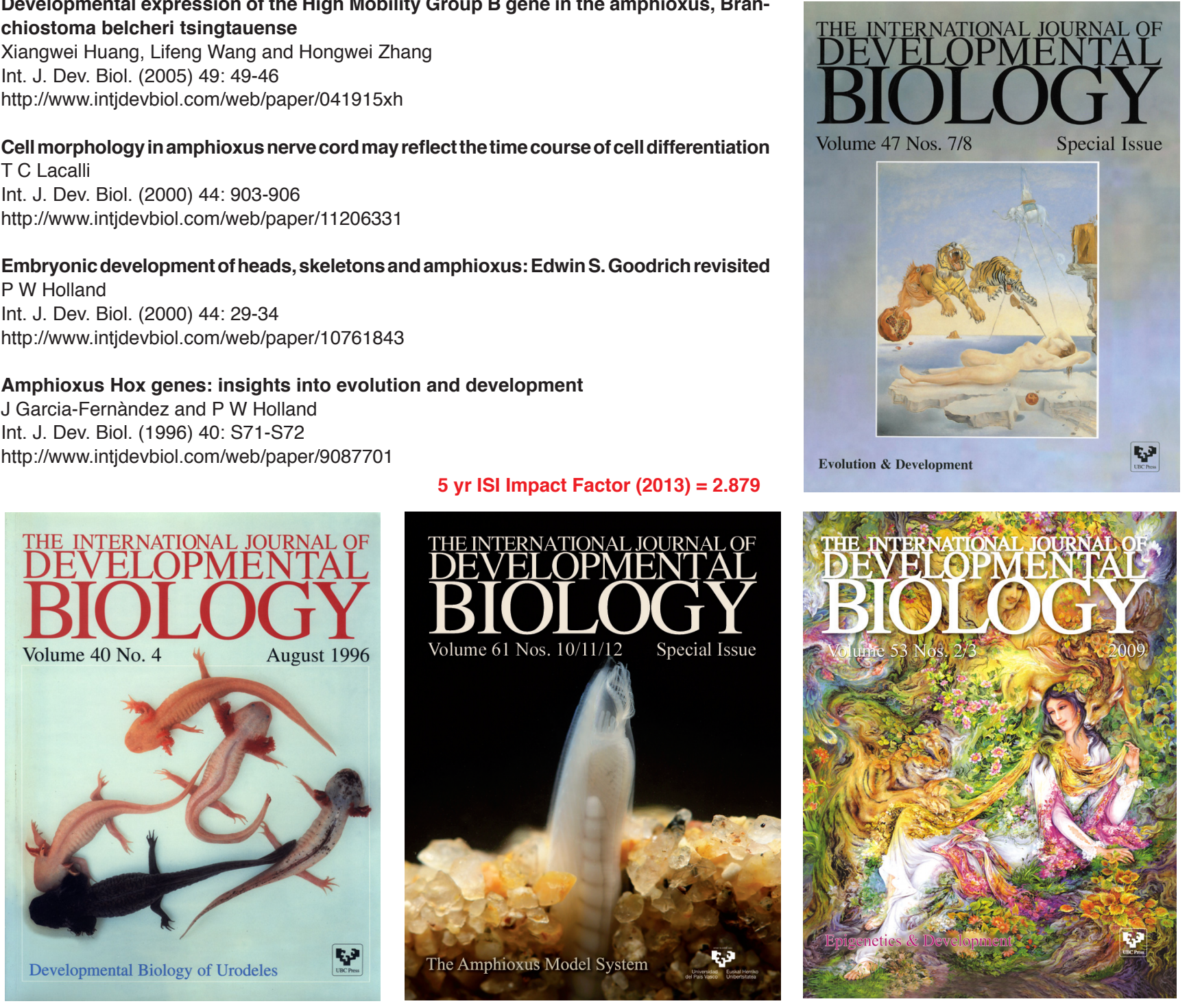